Objectives: To determine the frequency of multiple failure to bDMARDs in RA patients and to identify baseline/early features as possible predictors of multiple failure.

Methods: This case-control study involved subjects with $\mathrm{RA}^{1,2}$ treated with bDMARDs from the RA-Registry at La Paz Hospital between 2000 and 2019. Patients who presented insufficient response to $>3$ different bDMARDs or $>2$ bDMARDs with different mechanism of action were considered Multi-refractory (MR-patients). Patients who achieved low disease activity or remission (by DAS28) with the first bDMARD and maintained it in a follow-up period of at least 5 years were considered non-refractory (NR-patients). For all patients, demographic, clinical characteristics and laboratory parameters were assessed in the database at baseline visit, just prior to start bDMARD for first time and at 6-months visit.

Descriptive analysis was performed, and using the "refractory status" as the dependent variable, multiple bivariate logistic regression models were performed to identify which variables should be considered in the multivariate analyses. $\mathrm{P}<0.05$ was considered statistically significant. Odds Ratio (OR) and Confidence Intervals $(\mathrm{Cl})$ were calculated. IBM SPSS 21.0

Results: In total, 402 RA patients who had ever received bDMARD treatment were identified. According to pre-established inclusion criteria, 112 patients were included: 41 MR-patients (10\%) and 71 NR-patients (18\%). No differences in gender, age or age at RA diagnosis were found between both groups. Global time on bDMARD treatment was longer in MR-patients ( 11.7 vs 9.7 years, $p=0.01$ ) and survival on first bDMARD was $4.1 \pm 3.4$ years, which was decreasing with the successive treatments. In MR-patients, shorter disease duration between RA diagnosis and starting bDMARD (6.9 vs $10.0 ; p=0.04)$ and higher number of previous cDMARDs were observed. Also presence of erosions and extra-articular manifestations were more frequent in MR-patients ( $58.5 \%$ vs $25.4 \%, p=0.03$ and $29.3 \%$ vs $12.7 \%, p<0.001)$.

Results of variables included in bivariate and multivariate analyses are shown in Table 1. Finally, factors associated with multi-bDMARDs refractoriness in the multivariate analysis were presence of erosions, earlier age at bDMARD start, higher baseline DAS-28 and especially $\triangle \mathrm{DAS}<1.2$ in the first 6 months of treatment (OR 11.12; $95 \%$ Cl 3.34-26.82)

Table 1.

\begin{tabular}{|c|c|c|}
\hline VARIABLE & $\begin{array}{c}\text { Bivariate } \\
\text { OR }(95 \% \mathrm{Cl})\end{array}$ & $\begin{array}{l}\text { Multivariate } \\
\text { OR }(95 \% \mathrm{Cl})\end{array}$ \\
\hline Age at diagnosis & $0.99(0.96-1.0)$ & - \\
\hline Sex (Female) & $1.67(0.58-4.73)$ & $5.94(0.92-38.20)$ \\
\hline Age at bDMARD treatment & $0.97(0.93-1.00)$ & $0.95(0.90-0.99)$ \\
\hline Time between diagnosis and bDMARD & $0.94(0.89-1.00)$ & - \\
\hline Body mass index & $1.01(0.94-1.09)$ & - \\
\hline Erosions (ref yes) & $4.07(1.79-9.26)$ & $3.26(1.18-9.00)$ \\
\hline Extraarticular manifestations (ref yes) & $2.81(1.0-7.52)$ & $2.14(0.59-7.78)$ \\
\hline Metothrexate (ref yes) & $1.83(0.66-5.10)$ & - \\
\hline Previous cDMARDs & $3.54(2.05-6.1)$ & - \\
\hline CRP baseline & $1.02(0.99-1.05)$ & - \\
\hline DAS28 baseline & $1.77(1.2-2.6)$ & $2.29(1.39-3.76)$ \\
\hline$\Delta$ DAS-28 $($ ref $<1.2)$ & $0.22(0.09-0.52)$ & $11.12(3.34-26.82)$ \\
\hline HAQ baseline & $1.13(1.03-1.23)$ & $1.09(0.92-1.29)$ \\
\hline
\end{tabular}

Conclusion: In our cohort, $10 \%$ of patients with RA were observed to have multi-refractoriness to bDMARDs. This study also identified baseline and early clinical characteristics of patients as predictors of multi-refractoriness, especially absence of clinical response during the first 6 months on a first bDMARD.

References:

[1] Arnett FC. Arthritis Rheum 1988;31:315-24. ${ }^{2}$ Aletaha D. Arthritis Rheum. 2010;62:2569-81

Disclosure of Interests: Marta Novella-Navarro: None declared, Chamaida Plasencia: None declared, Carolina Tornero: None declared, Karen Nathalie Franco Gomez: None declared, Irene Monjo: None declared, Victoria Navarro-Compán Consultant of: Abbvie, Lilly, Novartis, Pfizer, UCB, Speakers bureau: AbbVie, MSD, Lilly, Novartis, Pfizer, UCB, Diana Peiteado: None declared, Alejandro Balsa Grant/research support from: BMS, Roche, Consultant of: AbbVie, Gilead, Lilly, Pfizer, UCB, Sanofi, Sandoz, Speakers bureau: AbbVie, Lilly, Sanofi, Novartis, Pfizer, UCB, Roche, Nordic, Sandoz DOI: 10.1136/annrheumdis-2020-eular.992

\section{AB0314 BIOLOGICAL THERAPY: SCREENING AND PREVENTION MODALITIES IN RHEUMATIC AND INFLAMMATORY BOWEL DISEASE PATIENTS}

S. Nsibi ${ }^{1}$, R. Ennaifer ${ }^{1}$, B. Bouchabou ${ }^{1}$, K. Ben Abdelghani ${ }^{2}$, A. Fazaa ${ }^{2}$, H. Ben Nejma ${ }^{1}$, A. Laatar ${ }^{2} .{ }^{1}$ Mongi Slim Hospital, Hepatology and Gastro-Enterology, La Marsa, Tunisia; ${ }^{2}$ Mongi Slim Hospital, Rheumatology, La Marsa, Tunisia
Background: Viral hepatitis $\mathrm{B}$ reactivation $(\mathrm{VHBr})$ is a serious complication of immunomodulatory therapy and in particular biological therapy (BT), which can be life-threatening, whence the adoption by societies of screening and prevention strategies based on the risk of $\mathrm{VHBr}$ which depends on serological status and the treatment used.

Objectives: The objective of our study was to determine the modalities of HBV screening, to describe the prevalence of HBV infection in this group of patients, and to evaluate the $\mathrm{VHBr}$ prevention strategies adopted in our country.

Methods: This was a retrospective, 8-year [2011-2018], single-centre, descriptive, retrospective study conducted in two departments: Rheumatology and Hepato-Gastroenterology. Patients under BT were included. Records with missing data were excluded. The modalities of screening and prevention of $\mathrm{VHBr}$ were determined and the prevalence of $\mathrm{HBV}$ markers was investigated.

Results: One hundred patients were included: 85 followed up for chronic inflammatory rheumatic disease: rheumatoid arthritis $(n=40)$, ankylosing spondylitis $(n=41)$, juvenile idiopathic arthritis $(n=4)$ and 15 patients followed up for inflammatory bowel disease (11 Crohn's disease and 4 ulcerative colitis). The mean age was 44 years with a predominance of females (59\%). The BTs prescribed were: anti-TNFa, anti-IL6 and antiCD20 in $83 \%, 11 \%$ and $7 \%$ respectively.

HBV screening was done in $89 \%$ of cases: HBsAg was tested in $89 \%$, anti-HBc in $64 \%$ and anti-HBs in $43 \%$. Complete B serology (HBsAg, anti-HBc and anti-HBs) was performed in $40 \%$

One patient had chronic hepatitis B on Entecavir for 3 years before starting anti-CD20 ( $\mathrm{HBsAg}(+)$, anti-HBc(+)). A previous contact with $\mathrm{HBV}$ as evidenced by isolated anti-HBs $(+)$ positivity was noted in 13 patients $(20 \%)$.

A negative $B$ serology was noted in 30 patients $(30 \%)$. The vaccination rate was $10 \%$.

Prophylaxis with Entecavir was indicated in 2 patients at high risk of viral $\mathrm{B}$ reactivation (candidates for anti-CD20 therapy and having anti- $\mathrm{HBc}(+)$ with undetectable viral load). One patient at moderate risk of reactivation (candidate for anti-TNF therapy and having anti-HBc(+)) was placed on Lamivudine for prophylaxis. Pre-emptive therapy based on monitoring of alanine aminotransferase (ALT) and HBV DNA levels every 1 to 3 months was indicated in 10 patients (with anti-HBc (+) and candidates for BT other than anti-CD20) but correctly applied in only 2 patients $(20 \%)$. The remaining eight patients were monitored only for ALT levels. No cases of viral reactivation B were objectified.

Conclusion: In our study, viral hepatitis B screening was done correctly in $40 \%$ of the cases. The rate of VHB vaccination was low (10\%) despite the low cost of the vaccine. Prophylactic and pre-emptive treatment for viral reactivation were correctly applied in 100 and $20 \%$ of cases respectively. This underlines the difficulties encountered in applying pre-emptive treatment when access to HBV DNA level determination is limited and warrants more vigilance prior to the prescription of BT.

Disclosure of Interests: None declared

DOI: 10.1136/annrheumdis-2020-eular.748

\section{$\mathrm{AB} 0315$ \\ RETENTION RATE OF ABATACEPT MONOTHERAPY IN AN ITALIAN MULTICENTRIC RHEUMATOID ARTHRITIS COHORT}

D. Iacono ${ }^{1}$, I. Pantano ${ }^{2}$, D. Birra ${ }^{3}$, G. Scalise ${ }^{1}$, M. A. Coscia ${ }^{2}$, V. Messiniti ${ }^{2}$, G. Loi ${ }^{3}$, A. Merchionda ${ }^{3}$, P. Moscato ${ }^{3}$, F. Ciccia ${ }^{2}{ }^{1}$ University of Campania Luigi Vanvitelli, Naples, Italy; ${ }^{2}$ univesity of Campania Luigi Vanvitelli, Naples, Italy;

${ }^{3}$ University of Salerno, Salern, Italy

Background: EULAR recommendations focus the importance of Methotrexate (MTX) therapy as a key element in the treatment of patients with Rheumatoid Arthritis (RA), alone as first line therapy and in combination with biological Disease Modifying Anti-rheumatic Drug (bDMARDs). Abatacep (CTLA4-Ig) in Europe is approved for the treatment of moderate to severe active RA in combination with MTX. Several patients, however, discontinue MTX for intolerance, side effects or contraindications, and real-life data demonstrate how, even in patients receiving therapy with MTX, compliance could be suboptimal. The only data on the use of abatacept in monotherapy come from the ORA-Registry, where a worse performance is observed in monotherapy patients.

Objectives: To evaluate a multicenter cohort of RA patients treated with Abatacept in patients underwent combined MTX therapy vs monotherapy.

Methods: We retrospectively evaluated RA patients, referring to 2 Italian rheumatology centers, treated with Abatacept monotherapy or in combination with MTX. We compared both persistence in therapy and the rate of remission/low disease activity according to Clinical Disease Activity Index (CDAI) between the 2 groups. 